\title{
Follow-up of Application of Plaster-of-Paris Casts for Non-infected Plantar Ulcers in Field Conditions*
}

\author{
G. SODERBERG $\dagger$ \\ Formerly Physiotherapist at Pogiri, Andhra Pradesh, India
}

\begin{abstract}
This investigation of the frequency of recurrence of plantar ulcer after the removal of a plaster cast showed that while the overall recurrence rate was $40 \%$, over half $(55 \%)$ recurred within the first 3 months after removal and $72 \%$ did so within 6 months. The recurrence rate was higher $(45 \%)$ in deformed feet than in "normal" feet $(36 \%)$. The importance of preventing development of a first ulcer is emphasized and the prophylactic effect of wearing microcellular rubber shoes is discussed.
\end{abstract}

\section{INTRODUCTION}

In the Danish Leprosy Control Project at Pogiri, Andhra Pradesh, the routine treatment of noninfected plantar ulcers consists of the application of below-knee walking plaster-casts, which are applied in the field as well as in hospital. These patients are followed up at regular intervals as far as is feasible in field conditions, and preliminary results of 549 cases were presented at the Ninth International Leprosy Congress, London, 1968, and at the Eleventh All India Leprosy Workers' Conference, New Delhi (see Cap et al., 1968).

Since then, information about 313 additional cases has become available. The total number of ulcers found to be cured at removal of the plaster-cast, and followed up after at least one year, amounts at present to 862 . The results are presented in this paper. The terminology and classification used are in accordance with the recommendations of the WHO Expert Committee.

\section{MATERIAL AND METHODS}

When this information was collected, some 27,300 patients were registered for treatment in the project, and 8016 had already been released from control. Out of a total of 35,316 patients

*Received for publication 20 October, 1969.

†Communications for the author should be addressed c/o Dr. J. A. Cap, WHO Leprologist, at Pogiri. under treatment or under observation, 9391 $(26.5 \%)$ have anaesthetic feet, and 2196 are suffering from plantar ulcers, i.e. $7.2 \%$ of the total number of patients or $23.4 \%$ of the patients with anaesthetic feet.

One of the objectives of the physiotherapy department is to prevent the development of plantar ulcers in patients with anaesthetic feet, through health education, and by providing them with simple nail-less microcellular rubber (MCR) shoes.

A plaster-cast is applied for non-infected plantar ulcers, but patients with infected ulcers are admitted to hospital for a few days and a P.O.P. (plaster-of-Paris) cast applied as soon as the infection has subsided. It is not known how many of the existing plantar ulcers in the project are non-infected and suitable for treatment with a plaster-cast.

The healing rate lies between 80 and $85 \%$. An ulcer is considered healed only when it is completely closed. When the ulcer is persistent, the failure is mainly due to thefact that patients themselves remove the cast shortly after application. Sometimes it happens that the plastercast is damaged in such a way that it becomes useless.

In the 862 cases which could be followed-up, and which form the subject of this study, the ulcer was found to be cured on removal of the 
plaster. It was intended to re-examine all those patients after a 12 -month period, but this was not possible in field conditions, because it would take several months before all clinics could be visited by the mobile physiotherapy team. It sometimes happened that the patient did not attend the programme although he was requested to do so, or he may have been absent from his village at the time. For these reasons the great majority of the patients were seen between 18 and 24 months, the average period being 19 months. In a very few cases, the period between removal of P.O.P. and follow-up was more than 3 years.

There was no difference in the recurrence rate in relation to the duration of the period of observation (see Table 1).

TABLE 1

Recurrence of plantar ulcers in relation to the period of observation after removal of the P.O.P.

\begin{tabular}{lrrrr}
\hline $\begin{array}{c}\text { Period of } \\
\text { observation } \\
\text { in months }\end{array}$ & \multicolumn{2}{c}{ Recurrence } & \multicolumn{2}{c}{ Total } \\
Number & $\%$ & Number & $\%$ \\
\hline 12-18 months & 175 & 42.4 & 413 & 47.9 \\
18-24 months & 116 & 40.0 & 29() & 33.6 \\
24-32 months & 42 & 36.8 & 114 & 13.2 \\
32-36 months & 5 & 31.2 & 16 & 1.9 \\
$\begin{array}{l}37-42 \text { months } \\
42 \text { months and }\end{array}$ & 4 & 33.3 & 12 & 1.4 \\
$\quad$ & 6 & 35.3 & 17 & 2.0 \\
over & 348 & 40.4 & 862 & 100.0 \\
\hline
\end{tabular}

\section{RESULTS}

\section{General}

As in the previous report (Cap et al., 1868) the recurrence rate is $40 \%, 348$ plantar ulcers having recurred out of the total group of 862 . The additional group of 313 patients with ulcers did not change the recurrence rate in any way.

As can be seen in Tables 2 and 3, there is no difference in the recurrence rate between the sexes, nor in relation to the form of leprosy; no patients with the indeterminate type of leprosy were treated for plantar ulcers with a plastercast, and the group under review therefore contains only those with lepromatous or tuberculoid leprosy.
TABLE 2

Recurrence of plantar ulcer after P.O.P. in relation to sex

\begin{tabular}{lcccc}
\hline \multirow{2}{*}{ Sex } & \multicolumn{2}{c}{ Recurrence } & \multicolumn{2}{c}{ Total } \\
& Number & $\%$ & Number & $\%$ \\
\hline Male & 229 & 39.7 & 577 & 66.9 \\
Female & 119 & 41.8 & 285 & 33.1 \\
Total & 348 & 40.4 & 862 & 100.0 \\
\hline
\end{tabular}

TABLE 3

Recurrence of plantar ulcers in relation to the classification

\begin{tabular}{lcccc}
\hline \multirow{2}{*}{ Classification } & \multicolumn{2}{c}{ Recurrence } & \multicolumn{2}{c}{ Total } \\
& Number & $\%$ & Number & $\%$ \\
\hline Lepromatous & 96 & 42.3 & 227 & 26.3 \\
Tuberculoid & 252 & 39.7 & 635 & 73.7 \\
Indeterminate & - & - & - & - \\
Total & 348 & 40.4 & 862 & 100.0 \\
\hline
\end{tabular}

Recurrence in relation to the period of time after removal

Information about the period of time which elapsed between removal of the plaster-cast and recurrence of the ulcer was obtained by questioning the patient and also from the notes on the treatment cards which were kept by the clinicworkers.

Table 4 shows that out of 862 healed ulcers, 193 or $22.3 \%$ recurred within 3 months and $29.2 \%$ within 6 months after removal of the P.O.P. From then onwards, the recurrence rate increases more slowly.

TABLE 4

Period of time between removal of P.O.P. and recurrence of plantar ulcer $(862$ cases $)$

\begin{tabular}{lcc}
\hline $\begin{array}{c}\text { Period after removal } \\
\text { in months }\end{array}$ & \multicolumn{2}{c}{ Recurrence } \\
\hline 0-3 months & 193 & $\%$ \\
3-6 months & 252 & 22.3 \\
6-9 months & 281 & 29.2 \\
9-12 months & 322 & 32.6 \\
12 months and over & 348 & 37.4 \\
& & 40.4 \\
\hline
\end{tabular}


TABLE 5

Period of time between removal of P.O.P. and recurrence of plantar ulcer

\begin{tabular}{lrr}
\hline $\begin{array}{c}\text { Period after removal } \\
\text { in months }\end{array}$ & Number & $\%$ \\
\hline 0-3 months & 193 & 55.4 \\
3-6 months & 59 & 17.0 \\
6-9 months & 29 & 8.3 \\
$9-12$ months & 41 & 11.8 \\
12 months and over & 26 & 7.5 \\
Total & 348 & 100.0 \\
\hline
\end{tabular}

Considering only the recurred ulcers, it can be seen from Table 5 that of 348 recurred ulcers more than $55.4 \%$ did so within the first 3 months after removal of the plaster. Nearly $72.4 \%$ had recurred before 6 months had elapsed. Only in 26 cases $(7.5 \%)$ did the ulcer recur after having been closed for more than 12 months.

The first few months immediately following the removal of the plaster-cast thus seem to be decisive in the possible recurrence of plantar ulcers.

\section{Duration of the ulcers}

In our previous study the impression was gained that the recurrence rate was higher in long-standing ulcers than in ulcers of short duration; out of 549 ulcers, 123 were reported to have been present less than one year before treatment. Of the latter, 39 or $31.7 \%$ recurred, while in the 426 long-standing ulcers 180 or $42.3 \%$ recurred.

In the present study the difference has flattened out; thus, 78 or $35.0 \%$ of the 223 ulcers with a duration of less than one year recurred, while of the 633 long-standing ulcers, 267 or $42.2 \%$ recurred. The difference is statistically not significant. (See Table 6.)

\section{Results in normal feet and in deformed feet}

In our previous study it was observed that of 295 patients with normal feet the ulcer recurred in 105 or $35.6 \%$, and that of the 254 patients with deformed feet, 114 or $44.9 \%$ suffered a recurrence. The opinion was then
TABLE 6

Recurrence of plantar ulcer in relation to its duration previous to the application of P.O.P.

\begin{tabular}{lccc}
\hline \multicolumn{1}{c}{$\begin{array}{c}\text { Duration of } \\
\text { plantar ulcer }\end{array}$} & \multicolumn{2}{c}{ Recurrence } & Total \\
& Number & $\%$ & \\
\hline 0-3 months & 30 & 36.1 & 83 \\
3-6 months & 25 & 32.1 & 78 \\
6-12 months & 23 & 37.1 & 62 \\
Less than 1 year & 78 & 35.0 & 223 \\
1 year & 104 & 39.0 & 267 \\
2-6 years & 120 & 42.1 & 285 \\
6-10 years & 35 & 52.2 & 67 \\
10 years and over & 8 & 57.1 & 14 \\
More than 1 year & 267 & 42.2 & 633 \\
Total & 345 & 40.3 & $856^{*}$ \\
\hline
\end{tabular}

*Information about duration of the plantar ulcer is not available for 6 patients: the ulcer recurred in 3 and did not recur in the 3 remaining.

expressed that the difference in the recurrence rate would increase still more if only those deformities which change the weight-bearing area were taken into consideration.

An attempt was therefore made to clarify this point and the present group was split into 3 sub-groups (see Table 7). This table shows that in 354 patients with otherwise normal feet, 128 or $36.2 \%$ had a recurrence of the ulcer.

The group of 189 patients with absorption of the feet is not very homogeneous and is therefore kept separately. It included patients with slight absorption of the toes, as well as patients with gross absorption and subsequent changes in the

TABLE 7

Recurrence of plantar ulcers after P.O.P. application in patients with deformed feet, and in patients with otherwise normal feet

\begin{tabular}{lcccc}
\hline & \multicolumn{2}{c}{ Recurrence } & \multicolumn{2}{c}{ Total } \\
& Number & $\%$ & Number & $\%$ \\
\hline Normal feet & 128 & 36.2 & 354 & 41.2 \\
Feet with & & & & \\
$\quad$ absorption & 75 & 39.7 & 189 & 21.9 \\
Deformed feet & 145 & 45.7 & 317 & 36.9 \\
Total & 348 & 40.5 & $860^{*}$ & 100.0 \\
\hline
\end{tabular}

*Information about status of foot missing in 2 cases. 
weight-bearing area; here 75 or $39.7 \%$ of them had recurrent ulcer. By "deformed feet" is mainly meant changes in the weight-bearing area due to previous bone involvement, and also drop-foot and combined deformities. Out of this group of 317 patients the ulcer recurred in 145 or $45.7 \%$.

It is obvious that with a more detailed and more scientifically reliable classification of the deformities, the percentage of recurrences in feet with a deformed weight-bearing area would still increase.

\section{Recurrence and site of the ulcers}

The recurrence rate is highest in feet with multiple ulcers (see Table 8). The great majority of these feet are deformed. Out of 139 patients with multiple ulcers, 73 or $52.5 \%$ recurred. In the group of 718 patients with single ulcers, the recurrence rate was $38.1 \%$.

Ulcers under the calcaneus recurred more frequently $(45.5 \%)$, followed closely by ulcers under the lst metatarsal head $(42.1 \%)$. Then come the ulcers under the other metatarsal heads and the great toe $(36 \%)$, and the lowest recurrence rate was observed in ulcers under the base of the 5 th metatarsal bone $(24.3 \%$ ). (See Table 8.)

TABLE 8

Recurrence of plantar ulcers in relation to the site

\begin{tabular}{lrrrr}
\hline \multicolumn{1}{c}{ Site } & \multicolumn{2}{c}{$\begin{array}{c}\text { Recurrence } \\
\text { Number }\end{array}$} & $\begin{array}{c}\text { Total } \\
\text { Number }\end{array}$ & $\%$ \\
& & & & \\
\hline Single ulcers & 40 & 45.5 & 88 & 10.3 \\
$\quad$ Calcaneus & 64 & 42.1 & 152 & 17.7 \\
1st metatarsal head & 24 & 36.4 & 66 & 7.7 \\
5th metatarsal head & & & & \\
2nd, 3rd and 4th & 88 & 36.2 & 243 & 28.4 \\
$\quad$ metatarsal head & 44 & 36.1 & 122 & 14.2 \\
Great toe & 9 & 24.3 & 37 & 4.3 \\
Base of 5th metatarsal & 5 & 50.0 & 10 & 1.2 \\
Other & & & & \\
Single ulcers & 274 & 38.1 & 718 & 83.8 \\
Multiple ulcers & 73 & 52.5 & 139 & 16.2 \\
Total & 347 & 40.5 & $857 *$ & 100.0 \\
\hline
\end{tabular}

* No information available about the site of the plantar ulcer in 5 patients: in 1 the ulcer recurred and in 4 it did not recur.
"Slippery slope"

Information was obtained from 837 patients about the existence of previous ulcers. The plaster-cast was applied for the first ulcer in 243 patients. It recurred in only 46 or $18.9 \%$ of them, as compared with a recurrence rate of $40.1 \%$ for the whole group. It is notable that where there had been a previous ulcer which left scar tissue after healing, the recurrence rate becomes more than twice as high. In a group of 217 patients who had had one ulcer previously, it recurred in 98 or $45.2 \%$. From then onwards the recurrence rate increases slowly from $48.5 \%$, when there were 2 previous ulcers, to $52.6 \%$ when there were more than 2 previous ulcers (see Table 9). These findings clearly show that the first ulcer is the most dangerous and should be avoided at all costs.

An attempt was then made to find out whether the ulcers which recurred almost immediately after removal of the plaster-cast (see p. 185) did so in patients with multiple

TABLE 9

Recurrence of plantar ulcers in relation to the previous ulcers (slippery slope)

\begin{tabular}{lcccc}
\hline & \multicolumn{2}{c}{ Recurrence } & \multicolumn{2}{c}{ Total } \\
& Number & $\%$ & Number & $\%$ \\
\hline I & 46 & 18.9 & 243 & 29.0 \\
II & 98 & 45.2 & 217 & 25.9 \\
III & 82 & 48.5 & 169 & 20.2 \\
IV-VIII & 110 & 52.6 & 209 & 24.9 \\
Total & 336 & 40.1 & $837 *$ & 100.0 \\
\hline
\end{tabular}

*Information about scars of previous ulcers is not available for 24 patients, 12 without recurrence of the ulcer and 12 with recurred ulcer.

I = The P.O.P. was applied for the first ulcer to occur, there having been no ulcer previously.

II = The P.O.P. was applied for the second ulcer, the first being cured with or without plaster-cast.

III : The P.O.P. was applied for the third ulcer, the first and second being cured with or without plaster-cast.

IV-VIII : Previous to the application of the plastercast, there had been 2 to 7 ulcers, which had been cured with or without application of P.O.P. 
TABLE 10

Distribution on "slippery slope" of patients whose ulcer recurred within 3 months after removal of the plaster-cast

\begin{tabular}{lcc}
\hline $\begin{array}{c}\text { Number of } \\
\text { ulcers }\end{array}$ & $\begin{array}{c}\text { Number of } \\
\text { patients }\end{array}$ & $\%$ \\
\hline I & 58 & 31.2 \\
II & 50 & 26.9 \\
III & 38 & 20.4 \\
IV-VIII & 40 & 21.5 \\
& & \\
Total & $186^{*}$ & 100.0
\end{tabular}

*Information about scars of previous ulcers is not available for 7 cases.

previous ulcers and extensive scar tissue. However, a comparison between Tables 9 and 10 shows that the proportion of patients for whom a plaster-cast was applied for 1, 2 or 3, or more previous ulcers, is the same in the total group as in the group in which the ulcer recurred within 3 months after removal.

\section{FOOTWEAR}

One of the points of the health education programme of the physiotherapy department is to convince patients with anaesthetic feet to wear MCR shoes.

The shoes are provided by the Project and cost about 10 rupees, but the patients can buy them from us for 3 rupees, which is about the same price as they pay for cheap, locally made shoes.

As a rule MCR shoes are not given free, so as to make sure that there is some personal motivation on the part of the patients.

TABLE 11

Number of patients with anaesthetic feet and having MCR shoes

\begin{tabular}{lcccc}
\hline & $\begin{array}{c}\text { Number of } \\
\text { patients with } \\
\text { anaesthetic } \\
\text { feet }\end{array}$ & $\begin{array}{c}\text { Number with shoes } \\
\text { Number }\end{array}$ & Number & $\%$ \\
& 7,195 & 365 & 866 & 12.0 \\
Without ulcers & Numb \\
With ulcers & 2,196 & 376 & 684 & 31.1 \\
Total & 9,391 & 741 & 1,450 & 15.4 \\
\hline
\end{tabular}

At present 1450 patients are wearing MCR shoes, or $15.4 \%$ of patients with anaesthesia of the feet, with or without ulcers (see Table 11). It is much easier to convince patients who are suffering from plantar ulcers to wear these shoes, and $31.1 \%$ of them have been provided with protective footwear.

Of the 7195 patients with anaesthesia of the feet without plantar ulcers, only 866 (or 12\%) have MCR shoes. It is, however, very encouraging to see that the number of patients in this category who are wearing MCR shoes has risen from 365 to 866 , an increase of $135 \%$. In the group of patients who had already had ulcers previously, the numbers rose from 376 to 684 , or by $82 \%$. The relative higher increase of shoe-wearing in the former group gives an indication of the influence of the healtheducation programme.

It is not possible in field conditions to have a measurement of the efficacy of footwear in the prevention of plantar ulcers, but data have been collected about the recurrence of plantar ulcers after P.O.P. in relation to the use of shoes.

It is rather surprising to find, as Table 12 shows, that there is little difference in the recurrence rate between patients who have MCR shoes and those who have not. Several explanations can be put forward. In this part of India footwear is uncommon among the agricultural population and lower social strata. The great majority of our patients belong to these categories, and although they are taught that they have to wear their shoes " 24 hours a day", it is not at all certain that they in fact do so.

TABLE 12

Recurrence of plantar ulcer after P.O.P. application, in patients with and without MCR shoes

\begin{tabular}{lcccc}
\hline \multicolumn{1}{c}{$\begin{array}{c}\text { Number of } \\
\text { patients }\end{array}$} & \multicolumn{2}{c}{ Recurrence } & \multicolumn{2}{c}{ Total } \\
& Number & $\%$ & Number & $\%$ \\
\hline $\begin{array}{l}\text { Patients with shoes } \\
\text { Patients without } \\
\text { shoes }\end{array}$ & 175 & 43.3 & 404 & 46.8 \\
Total & 173 & 37.7 & 458 & 53.2 \\
\hline
\end{tabular}


In other words, there may be a difference between "having shoes" and "wearing shoes".

The standard MCR shoes, when worn regularly, last for 4 to 6 months, but it sometimes happens that the patient neglects to have them repaired, or fails to replace them when they are beyond repair. Another reason is that patients who have had several ulcers previous to the P.O.P. application, and also those with deformed feet, are more willing to wear shoes. Out of 243 patients for whom a plaster-cast was applied for the first ulcer, 103 or $42.4 \%$ are

TABLE 13

Number of patients having MCR shoes in relation to the number of previous ulcers

\begin{tabular}{|c|c|c|c|c|c|}
\hline & \multirow{3}{*}{$\begin{array}{c}\text { Number } \\
\text { of } \\
\text { patients }\end{array}$} & \multicolumn{4}{|c|}{ Patients wearing $M C R$ shoes } \\
\hline & & \multicolumn{2}{|c|}{ Recurrence } & \multicolumn{2}{|c|}{ Total } \\
\hline & & Number & $\%$ & Number & $\%$ \\
\hline I & 243 & 21 & 20.4 & 103 & 42.4 \\
\hline II & 217 & 45 & 45.0 & 100 & 46.0 \\
\hline III & 169 & 40 & 51.2 & 78 & 46.1 \\
\hline IV-VIII & 209 & 69 & 56.2 & 123 & 58.8 \\
\hline Total & 837 & 175 & 43.3 & 404 & 48.2 \\
\hline
\end{tabular}

TABLE 14

Number of patients with normal and deformed feet, having MCR shoes

\begin{tabular}{|c|c|c|c|}
\hline & \multirow{2}{*}{$\begin{array}{c}\text { Number } \\
\text { of } \\
\text { patients }\end{array}$} & \multicolumn{2}{|c|}{$\begin{array}{l}\text { Number of patients } \\
\text { having MCR shoes }\end{array}$} \\
\hline & & Number & $\%$ \\
\hline Normal feet & 354 & 149 & 42.1 \\
\hline Feet with absorption & 189 & 75 & 40.2 \\
\hline Deformed feet & 317 & 180 & 56.8 \\
\hline Total & $860^{*}$ & 404 & 47.0 \\
\hline
\end{tabular}

*Information missing about 2 patients. wearing shoes, whereas 123 or $58.8 \%$ of the 209 patients who have had more than 3 ulcers previously have MCR shoes (see Table 13). Again, 149 patients $(41.8 \%$ ) with normal feet wear shoes, against $180(56.8 \%)$ of the 370 patients with deformed feet (see Table 14). Both groups represent the great majority of the patients for whom a plaster-cast has been applied, and their plantar ulcers are prone to recur whatever kind of footwear they are provided with; the footwear supplied by the Centre is unavoidably of a simple and standardized type, which may not be entirely suitable for such feet.

\section{SUMMARY AND CONCLUSIONS}

Over an average period of 19 months after removal of a plaster-cast for non-infected plantar ulcer, it was found that the ulcer had recurred in 348 or $40.4 \%$ of 862 patients whose ulcer had been healed at the time of removal of the plaster.

The first 6 months after removal of the plaster is the most dangerous period for recurrence of plantar ulcers: $72.4 \%$ of all recurrences took place during this period, and $55.4 \%$ occurred during the first 3 months after removal. No relationship was observed between the recurrence rate and sex, or classification and duration of the plantar ulcer previous to treatment.

The recurrence rate was higher $(45.7 \%)$ in 317 patients with deformed feet than in 354 patients with "normal" feet $(36.2 \%)$. The recurrence rate is also related to the site of the ulcer. The most important factor seems to be the presence of scar tissue due to previous

TABLE 15

Recurrence rate in patients with normal and deformed feet in relation to shoes

\begin{tabular}{|c|c|c|c|c|c|c|c|c|c|}
\hline & \multicolumn{3}{|c|}{ With shoes } & \multicolumn{3}{|c|}{ Without shoes } & \multicolumn{3}{|c|}{ Total number of patients } \\
\hline & No. & Recurred & $\%$ & No. & Recurred & $\%$ & No. & Recurred & $\%$ \\
\hline Normal feet & 149 & 59 & 39.6 & 205 & 69 & 33.6 & 354 & 128 & 36.2 \\
\hline Deformed feet & 180 & 85 & 47.2 & 137 & 60 & 43.8 & 317 & 145 & 45.7 \\
\hline Total & 404 & 175 & 43.3 & 456 & 173 & 37.9 & 860 & 348 & 40.4 \\
\hline
\end{tabular}


TABLE 16

Patients with P.O.P. application for ulcer under 5 th metatarsal head in relation to drop-foot

\begin{tabular}{lccc}
\hline & Recurred & $\begin{array}{c}\text { Not } \\
\text { recurred }\end{array}$ & Total \\
\hline Patients with drop-foot & 6 & 14 & 20 \\
Patients without drop-foot & 18 & 28 & 46 \\
Total & 24 & 42 & 66 \\
\hline
\end{tabular}

TABLE 17

Patients with P.O.P. application for ulcer under the base of 5 th metatarsal bone in relation to drop-foot

\begin{tabular}{lccc}
\hline & Recurred & $\begin{array}{c}\text { Not } \\
\text { recurred }\end{array}$ & Total \\
\hline Patients with drop-foot & 3 & 2 & 5 \\
Patients without drop-foot & 6 & 26 & 32 \\
Total & 9 & 28 & 37 \\
\hline
\end{tabular}

ulcers. Of a group of 243 patients for whom the plaster-cast was applied for the first ulcer, the ulcer recurred in only $45(18.9 \%)$. This clearly shows the absolute necessity of directing the greater part of our activities towards the prevention of the first ulcer, through health education, teaching patients with anaesthetic feet how to take care of them, and to persuade them to wear nail-less microcellular rubber shoes, of which simple standardized models are provided by the Project.

At present 1450 patients are wearing MCR shoes, or only $15.4 \%$ of those who ought to use protective footwear. It is encouraging to observe that the number of shoe-wearing patients who have anaesthetic feet but no plantar ulcer has increased in one year from 365 to 866 . The number of patients in this group who are wearing shoes has increased proportionally more than in the group of patients with plantar ulcers. It represents at present $12 \%$ of all patients (7195) with anaesthetic feet without plantar ulcer. It looks as if the health-education programme is slowly catching up in the prevention and treatment of plantar ulcers, and that gradually more and more patients are reached at the appropriate period, that is, before the ulcer develops.
In the Project no data are available concerning the value of protective footwear in the prevention of plantar ulcers.

The data presented with regard to the recurrence of plantar ulcers and the wearing of footwear are not very encouraging: the recurrence rate is the same in patients with shoes as in patients without shoes. But these figures may be misleading, since proportionally more patients with deformed feet and multiple previous and present plantar ulcers are wearing shoes; in these cases recurrence of the ulcer is very frequent and it is questionable whether the standardized type of shoes they are provided with do give full protection.

It is also not known how regularly the shoes are worn, not only because most people in the area are accustomed to walk bare-footed, but also because several social, economic, and even religious factors are not in favour of constant wearing of shoes. The health-education programme is being directed along these lines.

\section{ACKNOWLEDGEMENTS}

The author is very grateful to Dr. J. A. Cap, WHO Leprologist, for his encouragement and continuous assistance and guidance.

Thanks are also due to Mr. K. Venkateswara Rao, Mr. R. V. Ramana Murthy and Mr. V. Lakshman Das, physiotherapy-technicians, for their kind co-operation and help in collecting the data.

\section{REFERENCES}

BRAnd, P. (1966). Insensitive Feet. A Practical Handbook on Foot Problems in Leprosy. London: The Leprosy Mission.

CAP, J. A., SoderberG, G., KRAGH, L., MANi, R. S. and MADHAVA RAO, D. (1968). The role of physiotherapy in a control project. (Presented at the Ninth International Leprosy Congress, London, 1968. Abstract no. 56.) Int. J. Lepr. 36, 533.

SODERBERG, G., KRAGH, L., MANI, R. S. and MADHAVA RAO, D. (1969). Results of P.O.P. application for non-infected plantar ulcers in field conditions. (Presented at the Eleventh All India Leprosy Workers' Conference, New Delhi, 1969.)

Who EXPERT COMmitTeE ON Leprosy (1966). Third Report, Geneva. Wld Hlth Org. Tech. Rep. Ser., No. 319. 